\title{
Erosion dynamics in semi-arid areas of the Mediterranean Sea during past interglacials
}

\author{
CECILE LARA BLANCHET ${ }^{1}$, ARNE RAMISCH ${ }^{1,2}$, DR. \\ HANA JURIKOVA ${ }^{3,4}$, RIK TJALLINGII ${ }^{1}$, ANNE \\ OSBORNE $^{5}$, MARTIN FRANK ${ }^{4}$ AND ACHIM BRAUER ${ }^{1}$ \\ ${ }^{1}$ GeoForschungszentrum GFZ \\ ${ }^{2} \mathrm{KU}$ Leuven \\ ${ }^{3}$ University of St Andrews \\ ${ }^{4}$ GEOMAR Helmholtz Centre for Ocean Research Kiel \\ ${ }^{5}$ GEOMAR \\ Presenting Author: blanchet@gfz-potsdam.de
}

Understanding how landscapes respond to climatic changes is an important challenge. We use here sediment records from warm climate periods to explore the changes in erosion dynamics and identify the main drivers. Three case-studies will be presented that cover regions under different climatic regimes: the Dead Sea, the Nile deep-sea fan (DSF) and the gulf of Sirte offshore Libya. For this study, we will focus on present and past interglacials of the last 400 thousand years. Using radiogenic neodymium ( $\mathrm{Nd}$ ) and strontium ( $\mathrm{Sr}$ ) coupled to major elemental composition of various sedimentary fractions (carbonates, ironmanganese oxides, detrital fraction), we determine the changes in source of detrital sediments and potential decoupling due to climate-induced changes in weathering regimes and intensity. By combining these results with grain-size distribution and markers of precipitation and vegetation, we can investigate the feedback processes between transport modes, land cover and rainfall. Finally, the annual resolution of the records from the Dead Sea and the Nile DSF allow to determine the rate of changes over time scales relevant for human populations.

Both the Dead Sea and Nile deep-sea fan records show drastic changes in flood regimes at decadal time-scales during the Holocene that can be attributed to: i) changes in the precipitation modes, ii) internal monsoon dynamics and iii) non-linear responses of the catchment to changes in rainfall. Our case-study from the Nile DSF shows that vegetated watersheds can lead to high erosion rates. Erosion dynamics in Libya over the past 400 $\mathrm{kyr}$ is controlled by the sporadic reactivation of past river channels or aeolian deflation. With this case study, we investigate how fast the landscape transitioned from fluvial to aeolian and how these changes might have affected the seawater composition of the Mediterranean Sea and the Atlantic Ocean. We will finally compare results obtained on these different archives to other regional records and modelling results to provide an integrated picture of landscape reactivity in the southeastern Mediterranean region. 